\title{
Use of Direct Oral Anticoagulants in Patients With Antiphospholipid Syndrome: A Systematic Review and Comparison of the International Guidelines
}

\author{
Daniele Pastori ${ }^{\star}{ }^{+}$, Danilo Menichelli ${ }^{\dagger}$, Vittoria Cammisotto and Pasquale Pignatelli \\ Department of Clinical, Internal, Anesthesiological and Cardiovascular Sciences, Sapienza University of Rome, Rome, Italy
}

OPEN ACCESS

Edited by:

Tzu-Fei Wang,

University of Ottawa, Canada

Reviewed by:

Aurelien Delluc,

Ottawa Hospital, Canada

Bethany Samuelson Bannow,

Oregon Health and Science University,

United States

Camila Masias,

Baptist Health South Florida,

United States

*Correspondence:

Daniele Pastori

daniele.pastori@uniroma1.it

tThese authors have contributed equally to this work

Specialty section:

This article was submitted to

Thrombosis,

a section of the journal

Frontiers in Cardiovascular Medicine

Received: 27 May 2021

Accepted: 09 July 2021

Published: 03 August 2021

Citation:

Pastori D, Menichelli D, Cammisotto V and Pignatelli P (2021) Use of Direct Oral Anticoagulants in Patients With Antiphospholipid Syndrome: A Systematic Review and Comparison of the International Guidelines.

Front. Cardiovasc. Med. 8:715878. doi: 10.3389/fcvm.2021.715878
Antiphospholipid antibody syndrome (APS) requires long-term anticoagulation to prevent recurrent thrombosis. Direct oral anticoagulants (DOACs) have been increasingly used in APS patients, but contradictory guidelines recommendations on their use do exist. We performed a systematic review of literature including studies investigating the role of DOACs in APS patients. At this aim, PubMed and Cochrane databases were searched according to PRISMA guidelines. We identified 14 studies which investigated the use of DOACs in patients with APS, of which 3 randomized clinical trials (RCTs), 1 post-hoc analysis of 3 RCTs, 7 case series and 3 cohort studies (2 prospective and 1 retrospective). Among DOACs, rivaroxaban was the most used $(n=531)$, followed by dabigatran $(n=$ 90) and apixaban $(n=46)$. Regarding guidelines indications, the 2019 European Society of Cardiology (ESC) and American Society of Hematology (ASH) guidelines recommend against the use of DOACs in all APS patients. The European League Against Rheumatism (EULAR), British Society for Haematology (BSH), and International Society on Thrombosis and Haemostasis (ISTH) guidance provided more detailed indications stating that warfarin should be the first-choice treatment but DOACs may be considered in patients (1) already on a stable anticoagulation with a DOAC, (2) with low-quality anticoagulation by warfarin, (3) unwilling/unable to undergo INR monitoring, (4) with contraindications or serious adverse events under warfarin. Patients with arterial APS or triple positivity should be treated with warfarin while venous APS with single or double positivity may be candidate to DOACs, but high-quality studies are needed.

Keywords: vitamin K antagonists, direct oral anticoagulants, antiphospholipid antibody syndrome, guideline, anticoagulants

\section{INTRODUCTION}

The incidence and prevalence of antiphospholipid antibody syndrome (APS) are difficult to estimate given that the definition of APS has evolved over the years making epidemiological studies published before 2000 not adhering to the new classification criteria (1). However, a large recent study estimated an incidence of APS of 2.1 per 100,000 per year and a prevalence of 50 per 100,000 inhabitants (2). 
APS is an autoimmune disease characterized by the production of auto-antibodies directed against various phospholipids. APS is diagnosed in case of persistent positivity of anticardiolipin (aCL), anti- $\beta 2$ glycoprotein I ( $\beta 2 \mathrm{GPI})$, and lupus anticoagulant (LAC) assays, which also play a pathogenic role in determining the risk of thrombotic events (3). However, the persistent positivity to antiphospholipid antibodies (aPL) is not sufficient alone to define APS, which should be accompanied by clinical thrombotic event in the venous and arterial circulation or by obstetrical complications (4). Other non-criteria clinical manifestations in patients with APS include thrombocytopenia, which seems to have a negative prognostic role (5), neurological manifestations (6), and livedo reticularis (7), suggesting that clinical presentation may be heterogeneous and signs/symptoms are not limited to thrombosis.

Thrombotic manifestations are mainly related to the fact that aPL may directly contribute to thrombus formation and platelet activation (Figure 1). Indeed, an increased risk of myocardial infarction (8), ischemic stroke, and peripheral artery disease (9) and neurological disorders in this patient population has been described. After a first thrombotic event, the risk of recurrences sharply increases by $10-67 \%(10)$. The thrombotic risk seems to be influenced by the clinical and immunological characteristics of patients with triple positive aPL patients having the highest thrombotic risk, estimated at $5.3 \%$ per year $(11,12)$. However, the thrombotic potential of non-criteria aPL and the value of isolated IgM/LAC is still under investigation (13-15). Furthermore, a significant proportion of patients present a negativization of aPL during follow-up, but it is unclear if it parallels a reduction of thrombotic risk (16).

To reduce the risk of first and recurrent thrombotic events patients with APS require anti-thrombotic treatment. A metaanalysis showed that aspirin administration reduced the risk of first arterial (HR: 0.43 , 95\%CI $0.20-0.93$ ) but not venous thrombotic event in APS carriers (17). However, after a first thrombotic event, APS patients require long-term treatment with oral anticoagulants. For decades, vitamin K antagonists (VKAs) have represented the only available oral anticoagulant drug. However, some issues regarding the use of VKAs in patients with APS have become evident over time, including the so-called warfarin resistance [i.e., patients needing high weekly amount of VKAs to obtain and maintain therapeutic INR; (18)] and an unstable anticoagulation quality (19). In addition, a significant proportion of patients experience recurrent thrombotic events despite adequate anticoagulation (20), with high-intensity VKA therapy not being superior of standard care in reducing these recurrences (21). Moreover, the addition of aspirin to oral anticoagulation in recurrent arterial APS is still under debate given the lack of clear benefit (22). Finally, adherence to VKA treatment was shown to be progressively reduced over time in different clinical settings (23), with cessation of oral anticoagulation being associated with an increased risk of recurrent thrombotic events in APS $(24,25)$. For these reasons, adequate anticoagulation therapy still represents a clinical challenge in APS patients.

In the last decade, the direct oral anticoagulants (DOACs) have been increasingly used for the treatment of venous thromboembolism (VTE) and for the thromboprophylaxis of patients with atrial fibrillation. The main advantages of DOACs are the predictable anticoagulant effect, the fixed dose and the rapid onset and offset of action. More recently, the use of DOACs has been tested also in patients with APS with divergent results (26). Aim of this review is to summarize current evidence on the safety and efficacy of DOACs in APS and to compare recommendations provided by international scientific societies.

\section{STUDIES INVESTIGATING SAFETY AND EFFICACY OF DOACS IN APS PATIENTS}

\section{Information Sources and Search Strategy}

We performed a systematic review of literature including studies investigating the role of DOACs in APS patients. At this aim, PubMed and Cochrane databases were searched according to PRISMA guidelines. We included only clinical studies (both observational and randomized clinical trials) involving humans and in English language. Articles with no full text available were also excluded as well as review, commentary, and letters. We used a combination of "antiphospholipid syndrome" and "direct oral anticoagulants" or "apixaban," "dabigatran," "edoxaban," "rivaroxaban." No time restrictions were applied (last search performed on 27 Jun 2021). The use of "non-vitamin K oral anticoagulants" provided no additional results. Only one study from the same cohort was considered. Case series including $<5$ patients were excluded.

\section{Data Collection Process and Data Items}

Two physicians (DP and PM) independently screened the titles and abstracts of the manuscripts identified through the database searches to identify studies potentially eligible for further assessment. For each study, we collected the following information: Author (year), study design, follow up (months), triple positivity (\%), study sample, type of anticoagulant studied, women (\%), age (mean), index event for APS diagnosis, any safety endpoint, any efficacy endpoint.

\section{Quality Assessment}

Quality of included studies was assessed using the National Institutes of Health (NIH) Tools (https://www.nhlbi.nih.gov/ health-topics/study-quality-assessment-tools) according to each study type (Table 1): (1) Quality Assessment of Controlled Intervention Studies; (2) Quality Assessment of Controlled Intervention Studies; (3) Quality Assessment Tool for Case Series Studies; (4) Quality Assessment Tool for Observational Cohort and Cross-Sectional Studies.

\section{Study Characteristics and Quality Evaluation}

Strategy search and reasons for exclusion are reported in Figure 2. Table 2 reports clinical studies on the safety and efficacy of DOACs in APS patients. We identified 14 studies which investigated the use of DOACs in patients with APS, of which 3 randomized clinical trials (RCTs), 1 post-hoc analysis of 3 RCTs, 7 case series and 3 cohort studies (2 prospective and 1 retrospective) (Table 2). Quality evaluation 


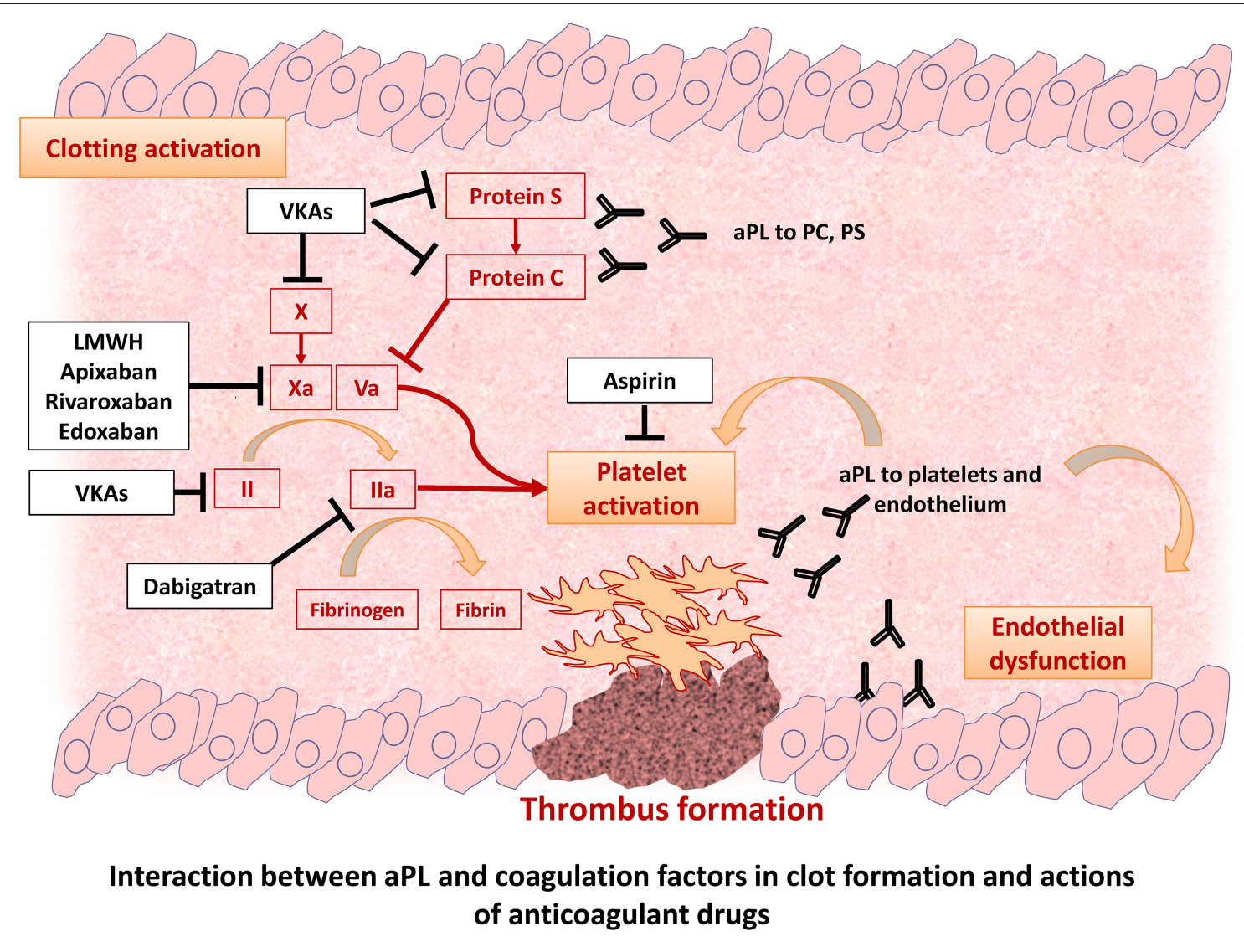

FIGURE 1 | Pathophysiology of thrombotic events in patients with antiphospholipid syndrome.

showed that the quality of RCT and post-hoc of RCT ranged from $8 / 14$ to $10 / 14$ mainly due to lack of blindness in treatment allocation, that is however, intrinsic in this type of studies comparing a dose-adjusted to a fixed-dose treatment (Table 1). The quality of case series was generally $4-5 / 9$ with only two studies scoring 6/9 (31) and 7/9 (39) (Table 1). These results are essentially due to a poor description of statistical methods (some of these series were published in form of brief report or letter) and lack of consecutive recruitment of patients (Table 1).

Regarding the 3 cohort studies, they generally lacked a formal sample size justification, blind adjudication of event, exposure assessment only at baseline and did not report the rate of patients lost during follow-up (Table 1).

Women represented the majority of patients among the studies, and the mean age of the population range between 39.1 and 53.4 years. Clinical events for the initiation of anticoagulation were mainly represented by venous thromboembolism, but two RCTs included both arterial and venous thrombosis as clinical index event. Two studies included also patients with obstetrical APS $(34,35)$, however, DOACs are not recommended in obstetrical APS and in lactating women, as they have a variable excretion rate in human milk and data on their safety are still lacking (41).
Among DOACs, rivaroxaban was the most represented with 531 treated patients, followed by dabigatran with 90 patients and apixaban with 46 patients. All RCTs (28-30) compared rivaroxaban with VKAs, while a post-hoc analysis of RE-MEDY and RE-COVER trials compared dabigatran with VKAs (27).

\section{Clinical Outcomes}

The follow-up ranged from 7 to 5 years (Table 2). The efficacy endpoints were the recurrence of VTE or a composite of arterial and venous thrombosis; safety endpoints were major or clinically relevant bleedings.

In two RCTs $(29,30)$ rivaroxaban was associated with an increased risk of thrombotic events without an increased risk of bleeding. Of note, these studies included APS patients with both arterial and venous thrombotic events and a high proportion of patients with triple positivity.

The only study which showed an increased risk of bleeding included mostly APS women $(>80 \%)$ with a high rate of heavy menstrual bleeding (HMB); while, no differences between two groups were reported regarding major, gastrointestinal or clinical relevant non-major bleeding (CRNMB) (32).

A post-hoc analysis of RE-MEDY and RE-COVER which compared dabigatran to VKAs (27) in patients with inherited disorders of whom APS represented the second most common 
TABLE 1 | Quality assessment for included studies.

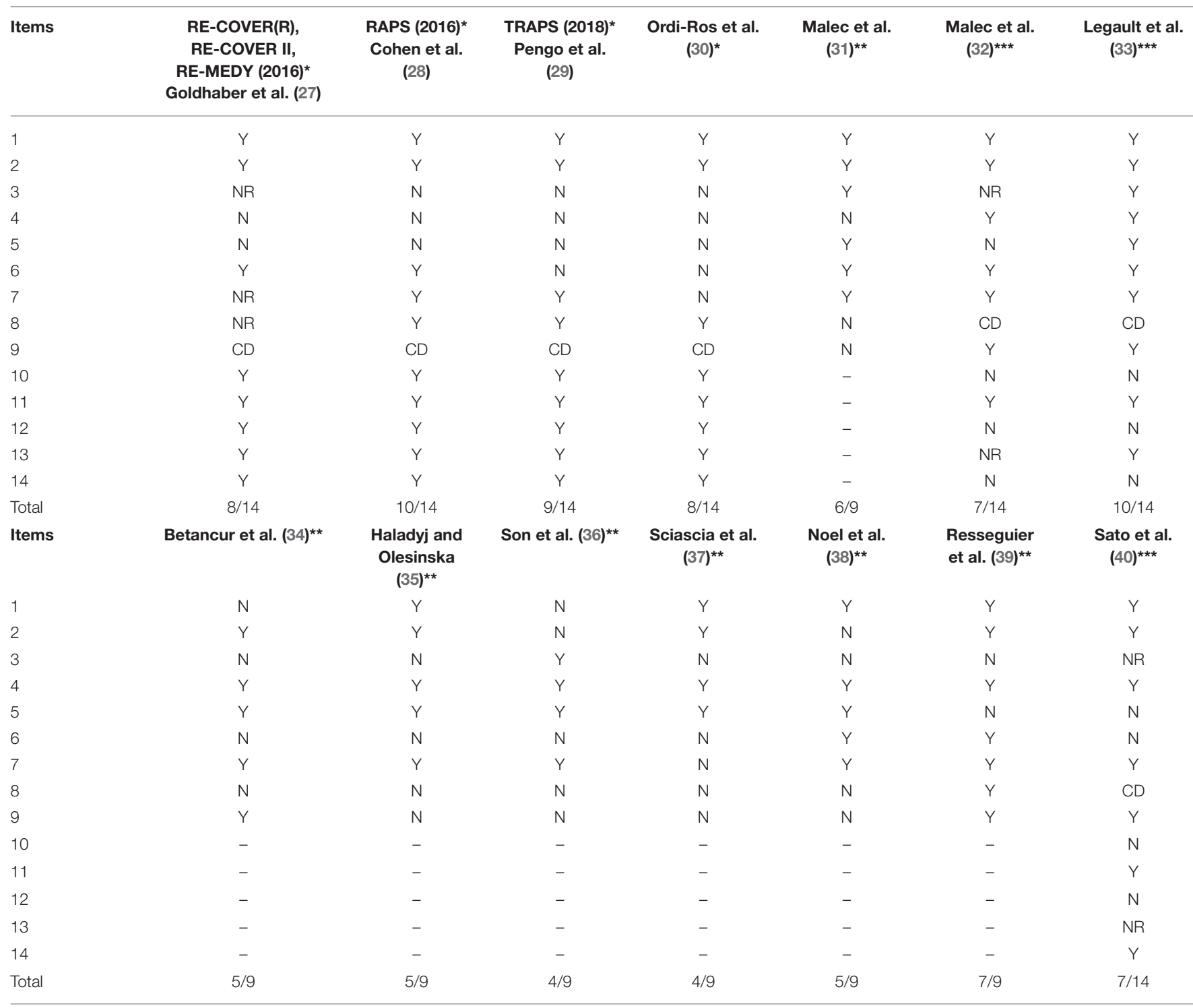

"Quality Assessment of Controlled Intervention Studies. (1) Was the study described as randomized, a randomized trial, a randomized clinical trial, or an RCT? (2) Was the method of randomization adequate (i.e., use of randomly generated assignment)? (3) Was the treatment allocation concealed (so that assignments could not be predicted)? (4) Were study participants and providers blinded to treatment group assignment? (5) Were the people assessing the outcomes blinded to the participants' group assignments? (6) Were the groups similar at baseline on important characteristics that could affect outcomes (e.g., demographics, risk factors, co-morbid conditions)? (7) Was the overall drop-out rate from the study at endpoint 20\% or lower of the number allocated to treatment? (8) Was the differential drop-out rate (between treatment groups) at endpoint 15 percentage points or lower? (9) Was there high adherence to the intervention protocols for each treatment group? (10) Were other interventions avoided or similar in the groups (e.g., similar background treatments)? (11) Were outcomes assessed using valid and reliable measures, implemented consistently across all study participants? (12) Did the authors report that the sample size was sufficiently large to be able to detect a difference in the main outcome between groups with at least $80 \%$ power? (13) Were outcomes reported or subgroups analyzed prespecified (i.e., identified before analyses were conducted)? (14) Were all randomized participants analyzed in the group to which they were originally assigned, i.e., did they use an intention-to-treat analysis?

"Quality Assessment Tool for Case Series Studies. (1) Was the study question or objective clearly stated? (2) Was the study population clearly and fully described, including a case definition? (3) Were the cases consecutive? (4) Were the subjects comparable? (5) Was the intervention clearly described? (6) Were the outcome measures clearly defined, valid, reliable, and implemented consistently across all study participants? (7) Was the length of follow-up adequate? (8) Were the statistical methods well-described? (9) Were the results well-described?

"*t" Quality Assessment Tool for Observational Cohort and Cross-Sectional Studies. (1) Was the research question or objective in this paper clearly stated? (2) Was the study population clearly specified and defined? (3) Was the participation rate of eligible persons at least 50\%? (4) Were all the subjects selected or recruited from the same or similar populations (including the same time period)? Were inclusion and exclusion criteria for being in the study prespecified and applied uniformly to all participants? (5) Was a sample size justification, power description, or variance and effect estimates provided? (6) For the analyses in this paper, were the exposure(s) of interest measured prior to the outcome(s) being measured? (7) Was the timeframe sufficient so that one could reasonably expect to see an association between exposure and outcome if it existed? (8) For exposures that can vary in amount or level, did the study examine different levels of the exposure as related to the outcome (e.g., categories of exposure, or exposure measured as continuous variable)? (9) Were the exposure measures (independent variables) clearly defined, valid, reliable, and implemented consistently across all study participants? (10) Was the exposure(s) assessed more than once over time? (11) Were the outcome measures (dependent variables) clearly defined, valid, reliable, and implemented consistently across all study participants? (12) Were the outcome assessors blinded to the exposure status of participants? (13) Was loss to follow-up after baseline $20 \%$ or less? (14) Were key potential confounding variables measured and adjusted statistically for their impact on the relationship between exposure(s) and outcome(s)?

$C D$, cannot be determined; NA, not applicable; NR, not reported; N, no; Y, yes. 


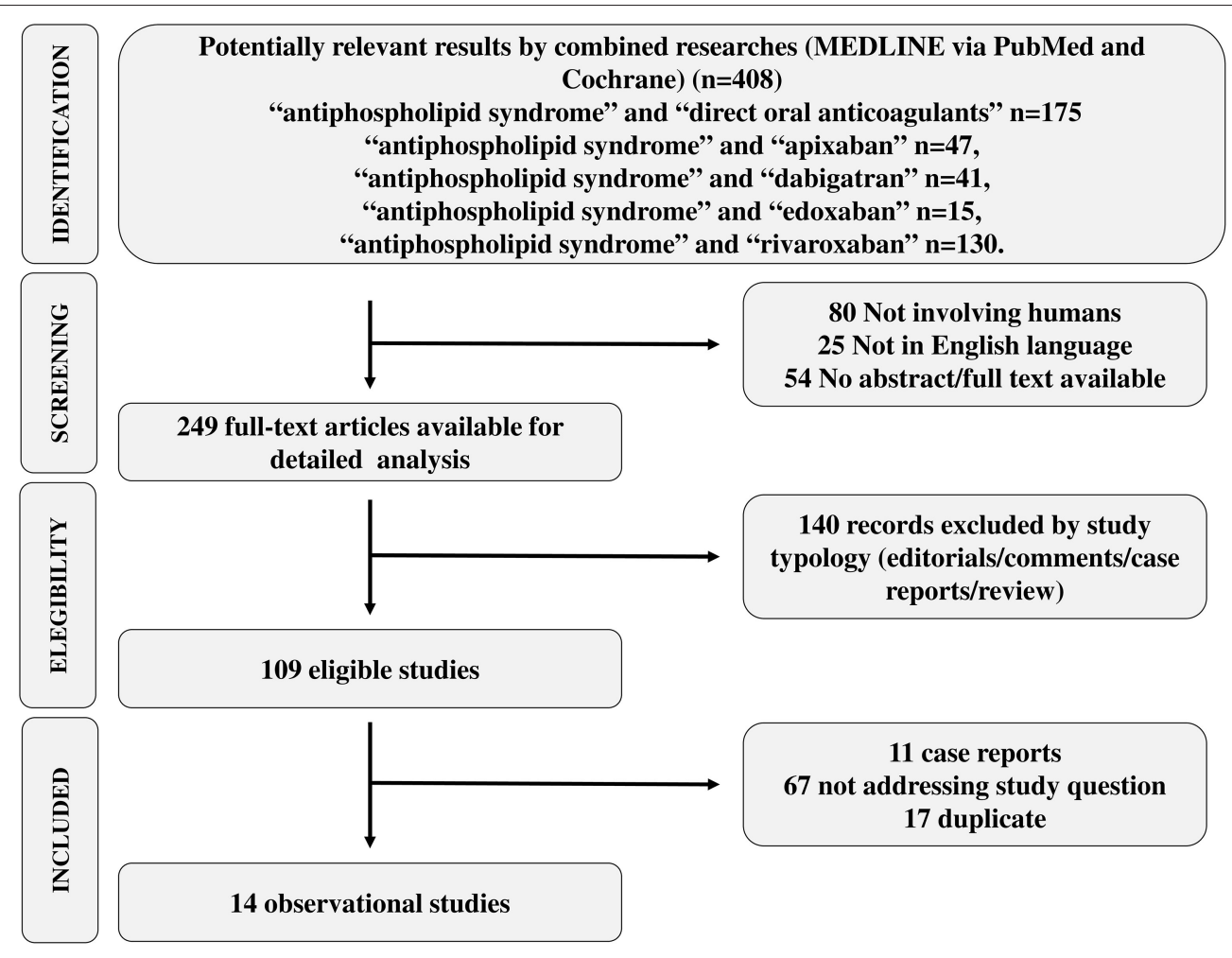

FIGURE 2 | PRISMA flow chart.

thrombophilia accounting for $20 \%$ of all patients (27), and a RCT (28), which compared rivaroxaban and VKAs showed similar safety and efficacy profiles between DOACs and VKAs (Table 2).

\section{GUIDELINES RECOMMENDATIONS/CONSENSUS SUGGESTIONS}

Based on the above discussed studies, different international thrombosis and cardiology societies provided discordant recommendations on the use of DOACs in patients with APS.

The grading system used to provide the level of evidence differed among guidelines and are reported in the footnote of the Table 3.

The 2019 European Society of Cardiology (ESC) guidelines recommend against the use of DOACs in APS patients, with no distinction among different DOACs, or between venous and arterial APS or among single, double or triple positive patients (Table 3). This recommendation seems however, to be based only on the results of the Trial on Rivaroxaban in AntiPhospholipid Syndrome (TRAPS) trial (29), which included triple positive thrombotic APS patients with both previous venous and arterial events, randomized to receive Rivaroxaban or conventional treatment. However, it should be noted that treatment of arterial events is not an indication to DOAC treatment. No mention is therefore given in case of venous or single/double positive APS patients. The results of this trial using Rivaroxaban were applied to all other DOACs.

Similarly, in the 2020 International Society on Thrombosis and Haemostasis (ISTH) guidance (46), DOACs are not considered as a valid option for any APS patient, with the only possibility of continuing DOAC in stable low-risk patients already on treatment, after shared informed discussion.

A more detailed indication on the use of DOACs is provided by the 2019 European League Against Rheumatism (EULAR) guidelines (47), which have taken into consideration the clinical phenotype of APS patients based on the presence of a venous or arterial event as indication to anticoagulation (Table 3). Thus, while DOACs and in particular Rivaroxaban, are contraindicated in APS patients with triple aPL positivity and/or an arterial event, its use may be considered in venous APS patients without triple aPL positivity (47). Another important difference between ESC and EULAR guidelines is that the latter consider the possibility that patients on VKAs may have low-quality therapy (i.e., low time in therapeutic range, TiTR) or may be intolerant to VKA treatment. In these cases, the use of DOACs may be considered (47).

A similar approach has been proposed by the 2020 British Society of Haematology (BSH) Guidelines, which suggest against the use of DOACs in arterial APS patients. In venous APS patients both triple and non-triple who are already on treatment 
TABLE 2 | Characteristics of studies enrolling patients with APS treated with DOACs.

\begin{tabular}{|c|c|c|c|c|c|c|c|c|c|c|}
\hline $\begin{array}{l}\text { Author } \\
\text { (year) }\end{array}$ & Design & $\begin{array}{l}\text { Follow up } \\
\text { (months) }\end{array}$ & $\begin{array}{l}\text { Triple } \\
\text { positive (\%) }\end{array}$ & $\begin{array}{l}\text { Study } \\
\text { sample }\end{array}$ & Anticoagulant & $\begin{array}{l}\text { Women } \\
\text { (\%) }\end{array}$ & $\begin{array}{l}\text { Age } \\
\text { (mean) }\end{array}$ & $\begin{array}{l}\text { Index } \\
\text { event }\end{array}$ & $\begin{array}{l}\text { Safety } \\
\text { endpoint }\end{array}$ & $\begin{array}{l}\text { Efficacy } \\
\text { endpoint }\end{array}$ \\
\hline $\begin{array}{l}\text { RE-COVER(R), } \\
\text { RE-COVER II, RE-MEDY } \\
\text { (2016) (27) }\end{array}$ & Post-hoc RCTs & $\mathrm{NR}$ & NR & 151 & $\begin{array}{l}\text { Dabigatran: } 71 \\
\text { VKA: } 80\end{array}$ & 36.4 & 47.6 & VTE & $\begin{array}{l}\text { MB (ISTH criteria), CRB } \\
\text { and any bleeding } \\
\text { Results: } \\
\text { Similar MB and CRBs. } \\
\text { Less any bleeding with } \\
\text { dabigatran (HR 0.50, } \\
\text { 95\%Cl 0.26-0.95) }\end{array}$ & $\begin{array}{l}\text { Recurrent } \\
\text { VTE/NTE-related death } \\
\text { Results: } \\
\text { Similar VTE between } \\
\text { dabigatran and warfarin } \\
\text { (HR 0.43, } \\
95 \% \mathrm{Cl} 0.08-2.38 \text { ) }\end{array}$ \\
\hline RAPS (2016) (28) & $\mathrm{RCT}$ & 7.0 & 28.0 & 116 & $\begin{array}{l}\text { Rivaroxaban: } 57 \\
\text { VKA: } 59\end{array}$ & 72.4 & 48.5 & VTE & $\begin{array}{l}\text { MB, CRB, and minor } \\
\text { bleedings } \\
\text { Results: } \\
\text { No MB or CRB occurred }\end{array}$ & $\begin{array}{l}\text { Thromboembolism } \\
\text { Results: } \\
\text { No thrombotic } \\
\text { events occurred }\end{array}$ \\
\hline TRAPS (2018) (29) & $\mathrm{RCT}$ & 20.4 & 100.0 & 120 & $\begin{array}{l}\text { Rivaroxaban: } 59 \\
\text { VKA: } 61\end{array}$ & 64.2 & 46.3 & $\begin{array}{l}\text { Arterial, venous, } \\
\text { and/or } \\
\text { biopsy-proven } \\
\text { micro-thrombosis. }\end{array}$ & \multicolumn{2}{|c|}{$\begin{array}{l}\text { Arterial or venous thromboembolic events, MB, and } \\
\text { vascular death } \\
\text { Results: } \\
13 \text { total events ( } 7 \text { thrombotic and } 6 \mathrm{MB}): 11 \text { (19\%) in } \\
\text { the rivaroxaban and } 2(3 \%) \text { in the warfarin group } \\
\text { Rivaroxaban: } 4 \mathrm{IS} \text { and } 3 \mathrm{MI} \text {, and } 4(7 \%) \mathrm{MB} \\
\text { Warfarin: no thrombotic events and } 2(3 \%) \mathrm{MB} \text {. No } \\
\text { death reported }\end{array}$} \\
\hline Ordi-Ros et al. (30) & $\mathrm{RCT}$ & 36.0 & 60.5 & 190 & $\begin{array}{l}\text { Rivaroxaban: } 95 \\
\text { VKA: } 95\end{array}$ & 63.7 & 49.0 & $\begin{array}{l}\text { Arterial or venous } \\
\text { thrombosis }\end{array}$ & $\begin{array}{l}\text { MB } \\
\text { Results: } \\
\text { MB occurred in } 6 \text { patients } \\
(6.3 \%) \text { in the rivaroxaban } \\
\text { group and } 7(7.4 \%) \text { in the } \\
\text { VKA group (RR 0.86, } \\
95 \% \mathrm{Cl} 0.30-2.46)\end{array}$ & $\begin{array}{l}\text { Venous } \\
\text { and arterial thrombosis } \\
\text { Results: } \\
11 \text { recurrent thrombosis } \\
\text { in the rivaroxaban and } 6 \\
\text { in the VKA group (RR } \\
1.83,95 \% \mathrm{Cl}, 0.71-4.76 \text { ) } \\
\text { More IS with rivaroxaban } \\
\text { (RR } 19.00 \text {, } \\
95 \% \mathrm{Cl}, 1.12-321.9 \text { ) }\end{array}$ \\
\hline Malec et al. (31) & $\begin{array}{l}\mathrm{P} \\
\text { Case series }\end{array}$ & 22.0 & 28.6 & 56 & $\begin{array}{l}\text { Rivaroxaban: } 49 \\
\text { Dabigatran: } 4 \\
\text { Apixaban: } 3\end{array}$ & 78.6 & 52.0 & VTE & $\begin{array}{l}\text { MB according to ISTH } \\
\text { criteria } \\
\text { Results: } \\
2 \text { severe bleedings }\end{array}$ & $\begin{array}{l}\text { VTE } \\
\text { Results: } \\
6 \text { (10.7\%) } \\
\text { VTE }(5.8 \% / \text { year })\end{array}$ \\
\hline Malec et al. (32) & P & 51.0 & 26.1 & 176 & $\begin{array}{l}\text { Rivaroxaban: } 36 \\
\text { Dabigatran: } 4 \\
\text { Apixaban: } 42 \\
\text { VKA: } 94\end{array}$ & 83.0 & 44.5 & $\begin{array}{l}\text { VTE or arterial } \\
\text { thrombosis }\end{array}$ & $\begin{array}{l}\text { MB or CRB } \\
\text { Results: } \\
\text { DOACs increased risk of } \\
\text { MB or CRNMB if } \\
\text { menstrual bleeding were } \\
\text { included (HR } 3.63,95 \% \mathrm{Cl} \\
1.53-8.63) \\
\text { Gl bleeds and MB or } \\
\text { CRNMB other than } \\
\text { menstrual bleeding were } \\
\text { similar between groups }\end{array}$ & $\begin{array}{l}\text { Composite of VTE, } \\
\text { cerebrovascular ischemic } \\
\text { events or MI } \\
\text { Results: } \\
\text { Increased thrombosis } \\
\text { with DOACs (HR 3.98, } \\
\text { 95\%Cl 1.54-10.28) and } \\
\text { recurrent VTE (HR 3.69, } \\
\text { 95\%Cl 1.27-10.68) } \\
\text { compared with VKAs }\end{array}$ \\
\hline Legault et al. (33) & P & 19.0 & 0.0 & 82 & Rivaroxaban & 47.6 & 53.4 & VTE & $\begin{array}{l}\text { MB } \\
\text { Minor bleeding } \\
\text { Results: } \\
\text { There were no MB but } 23 \\
\text { minor bleeding occurred }\end{array}$ & $\begin{array}{l}\text { VTE, myocardial } \\
\text { infarction, IS, and } \\
\text { cardiovascular death } \\
\text { Results: } \\
4 \text { thrombotic events ( } 2 \\
\text { cerebrovascular and } \\
2 \text { VTE) }\end{array}$ \\
\hline
\end{tabular}


TABLE 2 | Continued

\begin{tabular}{|c|c|c|c|c|c|c|c|c|c|c|}
\hline $\begin{array}{l}\text { Author } \\
\text { (year) }\end{array}$ & Design & $\begin{array}{l}\text { Follow up } \\
\text { (months) }\end{array}$ & $\begin{array}{l}\text { Triple } \\
\text { positive (\%) }\end{array}$ & $\begin{array}{l}\text { Study } \\
\text { sample }\end{array}$ & Anticoagulant & $\begin{array}{l}\text { Women } \\
\text { (\%) }\end{array}$ & $\begin{array}{l}\text { Age } \\
\text { (mean) }\end{array}$ & $\begin{array}{l}\text { Index } \\
\text { event }\end{array}$ & $\begin{array}{l}\text { Safety } \\
\text { endpoint }\end{array}$ & $\begin{array}{l}\text { Efficacy } \\
\text { endpoint }\end{array}$ \\
\hline Betancur et al. (34) & Case series & 19.0 & 12.5 & 8 & $\begin{array}{l}\text { Rivaroxaban: } 7 \\
\text { Apixaban: } 1\end{array}$ & 100.0 & 45.5 & $\begin{array}{l}\text { VTE }(87.5 \%), \text { PE } \\
(62.5 \%) \text {, and arterial } \\
\text { thrombosis }(75 \%) \text {, } \\
25 \% \text { obstetrical }\end{array}$ & - & $\begin{array}{l}\text { Recurrence of } \\
\text { thrombosis } \\
\text { Results: } \\
\text { There was no recurrence } \\
\text { of thrombosis }\end{array}$ \\
\hline $\begin{array}{l}\text { Haladyj and Olesinska } \\
\text { (35) }\end{array}$ & $\begin{array}{l}\mathrm{P} \\
\text { Case series }\end{array}$ & 20.0 & 17.4 & 23 & Rivaroxaban & 100.0 & NR & $\begin{array}{l}8 \text { arterial } \\
\text { thrombosis, } 9 \text { VTE, } \\
5 \text { both }\end{array}$ & $\begin{array}{l}\text { MB and minor bleeding } \\
\text { Results: } \\
\text { No MB or minor } \\
\text { bleeding occurred }\end{array}$ & $\begin{array}{l}\text { Arterial or venous } \\
\text { thrombosis } \\
\text { Results: } \\
1 \text { arterial thrombosis }\end{array}$ \\
\hline Son et al. (36) & $\begin{array}{l}\mathrm{P} \\
\text { Case series }\end{array}$ & 11.4 & 41.7 & 12 & Rivaroxaban & 58.3 & 42.0 & VTE and/or IS & - & $\begin{array}{l}\text { Recurrent DVT } \\
\text { Results: } \\
2 \text { patients had } \\
\text { recurrent DVT }\end{array}$ \\
\hline Sciascia et al. (37) & $\begin{array}{l}\mathrm{P} \\
\text { Case series }\end{array}$ & 10.0 & NR & 35 & Rivaroxaban & 68.6 & 47.0 & $\begin{array}{l}\text { Previous DVT (n: 24) } \\
\text { and } 11 \text { DVT and PE }\end{array}$ & $\begin{array}{l}\text { MB } \\
\text { Results: } \\
\text { No MB occurred }\end{array}$ & $\begin{array}{l}\text { VTE } \\
\text { Results: } \\
\text { No VTE occurred }\end{array}$ \\
\hline Noel et al. (38) & $\begin{array}{l}\mathrm{R} \\
\text { Case series }\end{array}$ & 19.0 & 26.9 & 26 & $\begin{array}{l}\text { Rivaroxaban: } 15 \\
\text { Dabigatran: } 11\end{array}$ & 53.8 & 39.1 & $\begin{array}{l}\text { Arterial and/or } \\
\text { venous thrombosis, } \\
\text { pregnancy morbidity }\end{array}$ & $\begin{array}{l}\text { Bleeding events } \\
\text { Results: } \\
2 \text { bleedings under } \\
\text { Rivaroxaban: one } \\
\text { hyper-menorrhea and one } \\
\text { rectal bleeding }\end{array}$ & $\begin{array}{l}\text { Thrombotic recurrence } \\
\text { Results: } \\
\text { One cutaneous } \\
\text { microthrombosis } \\
\text { under Rivaroxaban }\end{array}$ \\
\hline Resseguier et al. (39) & $\begin{array}{l}\mathrm{R} \\
\text { Case series }\end{array}$ & 35.6 & 8.7 & 23 & Rivaroxaban & 56.5 & 41.0 & $\begin{array}{l}\text { VTE }(n: 19) \text {, artery } \\
\text { event }(n: 2) \text { or both } \\
(n: 1) \text {, and } \\
\text { catastrophic APS } \\
(n: 1)\end{array}$ & $\begin{array}{l}\text { MB } \\
\text { Results: } \\
\text { No MB occurred }\end{array}$ & $\begin{array}{l}\text { Arterial and venous } \\
\text { thrombotic events } \\
\text { Results: } \\
\text { One patient } \\
\text { developed PE }\end{array}$ \\
\hline Sato et al. (40) & $\mathrm{R}$ & 5 years & 33.3 & 206 & $\begin{array}{l}\text { Factor Xa } \\
\text { Inhibitors: } 18 \\
\text { Warfarin: } 36\end{array}$ & 86.0 & 42.8 & $\begin{array}{l}34 \text { arterial } \\
32 \text { VTE } \\
11 \\
\text { pregnancy morbidity }\end{array}$ & $\begin{array}{l}\text { Severe bleeding requiring } \\
\text { hospitalization and/or } \\
\text { blood transfusion } \\
\text { Results: } \\
1 \text { and } 2 \text { cases of } \\
\text { recurrences of thrombosis } \\
\text { in the factor Xa } \\
\text { Inhibitors and warfarin } \\
\text { groups, respectively }\end{array}$ & $\begin{array}{l}\text { Arterial/venous } \\
\text { thrombosis } \\
\text { Results: } \\
6 \text { and } 8 \text { cases of } \\
\text { recurrences of } \\
\text { thrombosis in the factor } \\
\text { Xa } \\
\text { Inhibitors and warfarin } \\
\text { groups, respectively }\end{array}$ \\
\hline
\end{tabular}

Cl, confidence interval: CRB, clinical relevant bleeding: CRNMB, clinical relevant non-major bleeding: DOAC, direct oral anticoagulant; DVT, deep vein thrombosis; GI, gastrointestinal; HR, hazard ratio; IS, ischemic stroke; ISTH, International Society on Thrombosis and Haemostasis; MI, myocardial infarction; MB, major bleeding; NR, not reported; P, prospective; PE, pulmonary embolism; R, retrospective; RCT, randomized clinical trial; RR, relative risk; VKA, vitamin $K$ antagonist; VTE, venous thromboembolism. 
TABLE 3 | International guideline recommendations/consensus suggestions on the use of DOACs in APS patients.

\begin{tabular}{lll}
\hline Guidelines Recommendations & Level of evidence
\end{tabular}

ESC 2019 (42)

ASH 2020 (43)

NICE 2020 (44)

BSH Guidelines 2020 (45)

ISTH 2020 guidance (46)

EULAR 2019 (47)

\section{International guidelines on deep vein thrombosis/pulmonary embolism}

Indefinite treatment with a VKA is recommended for patients with APS

DOACs are not recommended in patients with severe renal impairment, during pregnancy and lactation, and in patients with APS

For patients with DVT and/or PE, the ASH guideline panel suggests using DOACs over VKAs (conditional recommendation based on moderate certainty in the evidence of effects). Remarks: This recommendation may not apply to certain subgroups of patients, such as those with renal insufficiency (creatinine clearance, $30 \mathrm{~mL} / \mathrm{min}$ ), moderate to severe liver disease, or APS

Offer people with confirmed proximal deep vein thrombosis or pulmonary embolism and an established diagnosis of triple positive APS LMWH concurrently with a VKA for at least 5 days, or until the INR is at least 2.0 in two consecutive readings, followed by a VKA on its own

\section{International guidelines on antiphospholipid syndrome}

Patients with arterial thrombosis

For anticoagulation for treatment and secondary prophylaxis of arterial thrombosis in patients with APS, we recommend VKAs and do not recommend DOACs

Patients with triple positive APS and venous thrombosis

We recommend against the initiation of DOACs for treatment or secondary prophylaxis in patients with venous thrombosis and known triple positive APS. For patients with triple positive APS who are currently on a DOAC, we recommend switching from the DOAC to a VKA after discussion with patients regarding the available evidence. For those patients who do not wish to switch, we recommend continuation of the DOAC over no anticoagulation

Patients with non-triple positive APS and venous thrombosis

There is insufficient evidence to make strong recommendations in this group of patients. We suggest against the initiation of DOACs for treatment or secondary prophylaxis in patients with venous thrombosis and known non-triple positive APS. Patients who are already on a DOAC may continue or switch to a VKA after discussion with the patient taking into account their clinical history, treatment adherence and previous experience. For those patients who do not wish to switch, we recommend continuation of the DOAC over no anticoagulation

We recommend that for the treatment of thrombotic APS among patients with any of the following (termed "high-risk" APS patients)

(a) triple positivity, (b) arterial thrombosis, (c) small vessel thrombosis or organ involvement (d) heart valve disease according to Sydney criteria, VKA should be used instead of DOACs

We recommend that DOACs should not be used in APS patients with recurrent thrombosis while on therapeutic intensity VKA. In this circumstance, other therapeutic options may include an increased target INR range, treatment dose $\mathrm{LMWH}$, or the addition of antiplatelet therapy

We recommend that DOACs should not be used in APS patients who are non-adherent to VKA. In this circumstance, other options may include education on adherence to VKA treatment along with frequent INR testing

In single or double positive non- "high risk" APS patients who have been on DOACs with good adherence for several months for a first episode of VTE, we recommend a discussion with the patient of options including perceived risks and uncertainties, in the spirit of shared decision-making and review of whether continued treatment with a DOAC is appropriate

In single- or double-positive non- "high-risk" APS patients with a single prior VTE requiring standard-intensity VKA, with allergy or intolerance to VKA or erratic INRs despite patient adherence, we suggest that alternative VKAs, if available, should be considered prior to consideration of a DOAC

In patients with definite APS and first venous thrombosis: Rivaroxaban should not be used in patients with triple aPL positivity due to the high risk of recurrent events In patients with definite APS and first venous thrombosis:

DOACs could be considered in patients not able to achieve a target INR despite good adherence to VKA or those with contraindications to VKA (e.g., allergy or intolerance to VKA)

In patients with definite APS and first arterial thrombosis:

Rivaroxaban should not be used in patients with triple APL positivity and arterial events

In patients with definite APS and first arterial thrombosis:

Based on the current evidence, we do not recommend use of DOACs in patients with definite APS and arterial events due to the high risk of recurrent thrombosis
$\mathrm{Ib}^{*}$

IIIc $c^{*}$

Remark. Evidence not provided

$\wedge$

$1 \mathrm{~B}^{\#}$

IB $^{\#}$

$\| C^{\#}$

Not provided

Not provided

Not provided

Not provided

Not provided

$1 b / B^{\S}$

$5 / D^{\S}$

$\mathrm{lb} / \mathrm{B}^{\S}$

$5 / D^{\S}$

APS, antiphospholipid antibody syndrome; ASH, American Society of Hematology; BSH, British Society for Haematology; DOAC, direct oral anticoagulant; DVT, deep vein thrombosis; ESC, European Society of Cardiology; EULAR, European League Against Rheumatism; INR, international normalized ratio; ISTH, International Society on Thrombosis and Haemostasis; LMWH, low-molecular weight heparin; NICE, National Institute for Health and Care Excellence; PE, pulmonary embolism; VKA, vitamin K antagonist; VTE, venous thromboembolism.

"ESC Committee for Practice Guidelines (CPG) policy.

$\S$ Oxford Centre for Evidence-Based Medicine standards.

\#Grading of Recommendations Assessment, Development and Evaluation (GRADE).

$\wedge$ Based on the Medicines and Healthcare products Regulatory Agency alert and the experience and opinion of the Guideline Committee. 


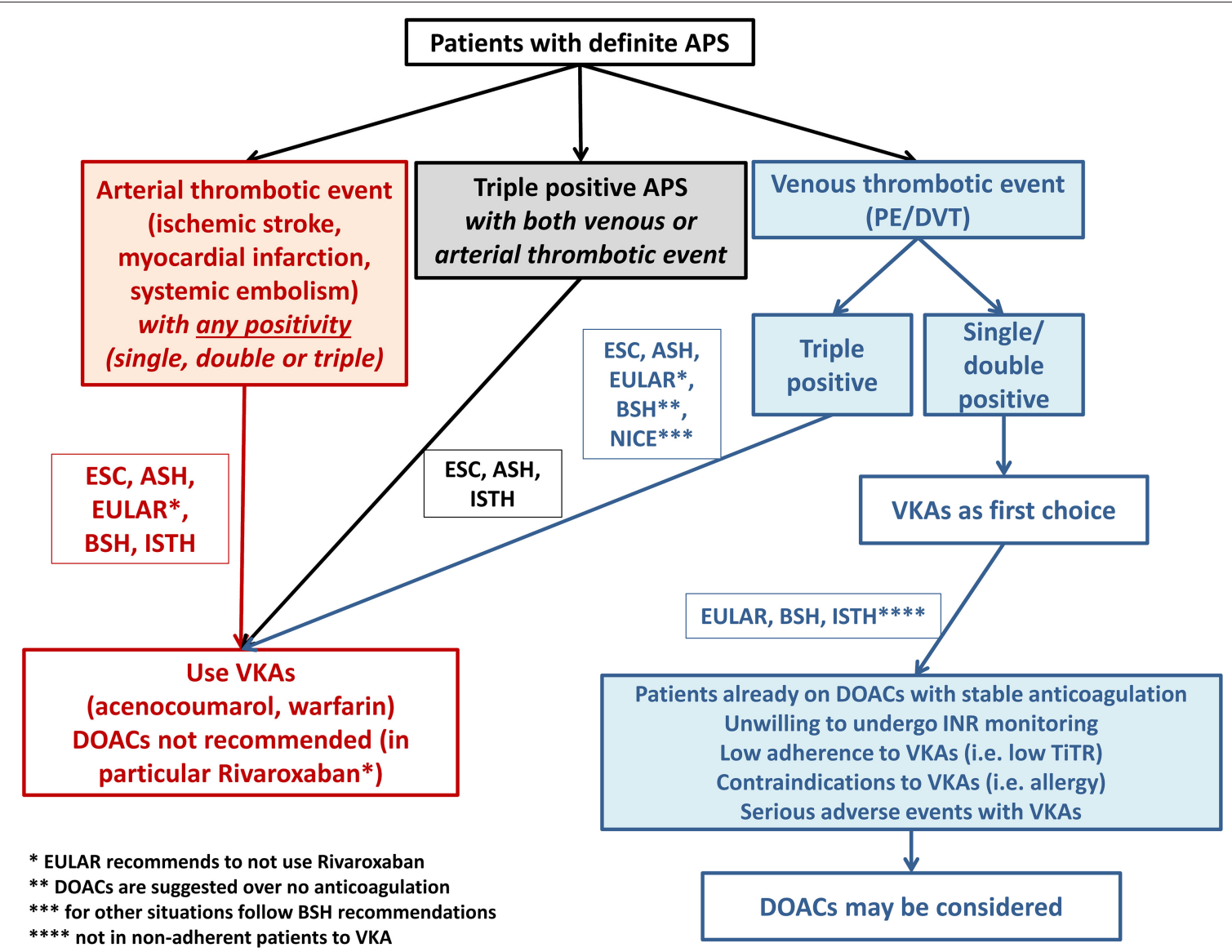

FIGURE 3 | Summary of guidelines recommendations on anticoagulant treatment prescription in patients with antiphospholipid syndrome.

with DOACs, treatment may be continued if patients refuse to switch to VKAs (45).

The 2020 American Society of Hematology (ASH) guidelines (43) state that APS patients are not optimal candidate for DOAC treatment, and suggest the use of low molecular weight heparin (LMWH) over DOAC in case of recurrent event under VKAs. However, the Authors acknowledge that this recommendation is based on very low certainty of the evidence of effects.

\section{DISCUSSION/OBSERVATIONS}

This systematic review of clinical studies showed that the safety and efficacy of DOACs may be highly dependent on clinical and immunological phenotype of APS patients. Of note, none of the studies including non-triple venous APS patients reported an excess of thrombotic recurrence, which was conversely more evident in studies including triple positive or arterial APS patients. It is therefore important to identify the clinical phenotype of patients with APS to establish in which subgroup the use of DOACs may be beneficial. In this context, a recent meta-analysis confirmed this approach showing a four-fold higher thrombotic risk in APS patients with triple positivity (56 vs. $23 \%$; OR $=4.3$, 95\%CI $2.3-7.7, p<0.0001)$ as well as in patients with a history of arterial thrombosis (32 vs. $14 \%$; OR = $2.8,95 \%$ CI $1.4-5.7, p=0.006)$ on treatment with DOACs (12).

The results from these studies have been differently received by expert committees of international societies to provide clinical recommendations on the use of DOACs in this patient population. Figure 3 summarizes current indications provided by international guidelines on the use of oral anticoagulants in patients with APS. While there is a general agreement on the contraindication on the use of DOACs, and in particular rivaroxaban, in patients with arterial APS and/or triple positivity, there are some differences regarding venous and non-triple APS patients.

Thus, while the ESC and ASH guidelines do not recommend the use of DOACs in any APS patients (with no level of evidence reported in the latter), there was an effort from EULAR, BSH, and ISTH to take into consideration the clinical phenotype of patients for choosing the most appropriate anticoagulant drug (Figure 3). These societies state that VKAs should always represent the firstchoice treatment in venous non-triple APS but open to the possibility of using DOACs in some specific situations and in any cases after a shared informed decision with the patient. In particular, patients diagnosed with APS after VTE but who are 
already on a stable anticoagulation with a DOAC may be kept on the same treatment, as the benefit of switching to VKAs may not be evident in this case. Similarly, patients with very lowquality anticoagulation by VKAs (i.e., TiTR $<60 \%$ ), experiencing INR instability and needing frequent INR checks may benefit more from a stable anticoagulation provided by fixed dose DOAC. Another group potentially suitable for DOAC treatment is represented by patients unwilling or unable to undergo INR monitoring as in the case of difficult access to healthcare facilities or impaired mobility, as treatment with DOAC may be beneficial over not treatment. Finally, patients with contraindications (i.e., allergy) or serious adverse events under VKA therapy may be considered for DOAC treatment. However, it should be noted that the indications provided by the ISTH is based on an expert consensus and no level of evidence for such recommendations is given.

Regarding the type of DOAC, rivaroxaban has been the most widely investigated drug, while the number of patients treated with dabigatran or apixaban is still low. A randomized trial investigating the efficacy and safety of Apixaban in APS patients is currently ongoing and has been modified to exclude patients with arterial thrombosis based on literature data (48); however, this study is actually closed. Patients who were enrolled are still being followed, although it is unclear if they are still being maintained on apixaban or not. No data regarding the use of edoxaban in this patient population are available.

Although DOACs do not require laboratory monitoring to ascertain their efficacy, the assessment of blood concentration

\section{REFERENCES}

1. Miyakis S, Lockshin MD, Atsumi T, Branch DW, Brey RL, Cervera R, et al. International consensus statement on an update of the classification criteria for definite antiphospholipid syndrome (APS). J Thromb Haemost. (2006) 4:295-306. doi: 10.1111/j.1538-7836.2006.01753.x

2. Duarte-Garcia A, Pham MM, Crowson CS, Amin S, Moder KG, Pruthi RK, et al. The epidemiology of antiphospholipid syndrome: a population-based study. Arthritis Rheumatol. (2019) 71:1545-52. doi: 10.1002/art.40901

3. Meroni PL, Borghi MO, Raschi E, Tedesco F. Pathogenesis of antiphospholipid syndrome: understanding the antibodies. Nat Rev Rheumatol. (2011) 7:330-9. doi: 10.1038/nrrheum.2011.52

4. Giannakopoulos B, Krilis SA. The pathogenesis of the antiphospholipid syndrome. N Engl J Med. (2013) 368:1033-44. doi: 10.1056/NEJMra1112830

5. Pardos-Gea J, Marques-Soares JR, Bujan S, Ordi-Ros J, Alijotas-Reig J. Persistent thrombocytopenia predicts poor long-term survival in patients with antiphospholipid syndrome: a 38-year follow-up study. Rheumatology. (2021). doi: 10.1093/rheumatology/keab475. [Epub ahead of print].

6. Bucci T, Menichelli D, Pignatelli P, Triggiani M, Violi F, Pastori D. Relationship of antiphospholipid antibodies to risk of dementia: a systematic review. $J$ Alzheimers Dis. (2019) 69:561-76. doi: 10.3233/JAD-181294

7. Miyamae T, Kawabe T. Non-criteria manifestations of juvenile antiphospholipid syndrome. J Clin Med. (2021) 10:1240. doi: $10.3390 / \mathrm{jcm} 10061240$

8. Pastori D, Bucci T, Triggiani M, Ames PRJ, Parrotto S, Violi F, et al. Immunoglobulin G (IgG) anticardiolipin antibodies and recurrent cardiovascular events. A systematic review and Bayesian meta-regression analysis. Autoimmun Rev. (2019) 18:519-25. doi: 10.1016/j.autrev.2019.03.005

9. Merashli M, Bucci T, Pastori D, Pignatelli P, Marottoli V, Arcaro A, et al. Antiphospholipid antibodies and lower extremity peripheral artery disease: a of DOACs may turn particularly useful for patients with APS to verify if appropriate peak and trough concentrations are obtained after the drug administration. These values have been shown to correlate with bleeding or thrombotic complications (49). In this context, previous evidence showed that the twice-daily dosing regimens with Apixaban and Dabigatran are associated with less high peak or low trough concentrations (50). More importantly, these twicedaily drugs might guarantee a more stable anticoagulation level in APS patients, leaving patients less exposed to low trough concentrations which are associated with thrombotic events (51).

In conclusion, international guidelines agree on the exclusive use of VKAs in patients with arterial APS and triple positivity (Figure 3). Evidence on venous APS is weak and patients with single or double positivity may be candidate to DOACs, after a shared informed decision with patients, especially in patients who are not willing or have contraindications to VKAs. The lack of consensus among guidelines/consensus originate from the paucity of randomized studies and the lack of rigorous patients' stratification.

\section{AUTHOR CONTRIBUTIONS}

DP and DM: conceptualization and draft of the manuscript. VC and PP: design and revision of the manuscript. All authors provide approval for publication of the content.

systematic review and meta-analysis. Semin Arthritis Rheum. (2020) 50:12918. doi: 10.1016/j.semarthrit.2020.08.012

10. Lim W, Crowther MA, Eikelboom JW. Management of antiphospholipid antibody syndrome: a systematic review. JAMA. (2006) 295:10507. doi: 10.1001/jama.295.9.1050

11. Pengo V, Ruffatti A, Legnani C, Testa S, Fierro T, Marongiu F, et al. Incidence of a first thromboembolic event in asymptomatic carriers of highrisk antiphospholipid antibody profile: a multicenter prospective study. Blood. (2011) 118:4714-8. doi: 10.1182/blood-2011-03-340232

12. Dufrost V, Risse J, Reshetnyak T, Satybaldyeva M, Du Y, Yan XX, et al. Increased risk of thrombosis in antiphospholipid syndrome patients treated with direct oral anticoagulants. Results from an international patient-level data meta-analysis. Autoimmun Rev. (2018) 17:1011-21. doi: 10.1016/j.autrev.2018.04.009

13. Chayoua W, Yin DM, Kelchtermans H, Moore GW, Gris JC, Musial J, et al. Is there an additional value in detecting anticardiolipin and anti-beta2 glycoprotein I IgA antibodies in the antiphospholipid syndrome? Thromb Haemost. (2020) 120:1557-68. doi: 10.1055/s-0040-1714653

14. Pignatelli P, Ettorre E, Menichelli D, Pani A, Violi F, Pastori D. Seronegative antiphospholipid syndrome: refining the value of "non-criteria" antibodies for diagnosis and clinical management. Haematologica. (2020) 105:56272. doi: 10.3324/haematol.2019.221945

15. Yin D, De Groot PG, Ninivaggi $M$, Devreese KMJ, De Laat B. Clinical relevance of isolated lupus anticoagulant positivity in patients with thrombotic antiphospholipid syndrome. Thromb Haemost. (2020). doi: 10.1055/a-1344-4271. [Epub ahead of print].

16. Radin M, Schreiber K, Sciascia S, Roccatello D, Cecchi I, Aguirre Zamorano MA, et al. Prevalence of antiphospholipid antibodies negativisation in patients with antiphospholipid syndrome: a long-term follow-up multicentre study. Thromb Haemost. (2019) 119:1920-6. doi: 10.1055/s-0039-1696687 
17. Arnaud L, Mathian A, Devilliers H, Ruffatti A, Tektonidou M, Forastiero R, et al. Patient-level analysis of five international cohorts further confirms the efficacy of aspirin for the primary prevention of thrombosis in patients with antiphospholipid antibodies. Autoimmun Rev. (2015) 14:192-200. doi: 10.1016/j.autrev.2014. 10.019

18. Ames PR, Margaglione M, Ciampa A, Colaizzo D, Ferrara F, Iannaccone $\mathrm{L}$, et al. Increased warfarin consumption and residual fibrin turnover in thrombotic patients with primary antiphospholipid syndrome. Thromb Res. (2011) 127:595-9. doi: 10.1016/j.thromres.2011. 01.014

19. Pastori D, Parrotto S, Vicario T, Saliola M, Mezzaroma I, Violi F, et al. Antiphospholipid syndrome and anticoagulation quality: a clinical challenge. Atherosclerosis. (2016) 244:48-50. doi: 10.1016/j.atherosclerosis.2015. 10.105

20. Radin M, Schreiber K, Cecchi I, Roccatello D, Cuadrado MJ, Sciascia S. The risk of ischaemic stroke in primary antiphospholipid syndrome patients: a prospective study. Eur J Neurol. (2018) 25:320-5. doi: 10.1111/ene. 13499

21. Finazzi G, Marchioli R, Brancaccio V, Schinco P, Wisloff F, Musial $\mathrm{J}$, et al. A randomized clinical trial of high-intensity warfarin vs. conventional antithrombotic therapy for the prevention of recurrent thrombosis in patients with the antiphospholipid syndrome (WAPS). J Thromb Haemost. (2005) 3:848-53. doi: 10.1111/j.1538-7836.2005. 01340.x

22. Bala MM, Celinska-Lowenhoff M, Szot W, Padjas A, Kaczmarczyk M, Swierz MJ, et al. Antiplatelet and anticoagulant agents for secondary prevention of stroke and other thromboembolic events in people with antiphospholipid syndrome. Cochrane Database Syst Rev. (2020) 10:CD012169. doi: 10.1002/14651858.CD012169.pub3

23. Martinez C, Katholing A, Wallenhorst C, Freedman SB. Therapy persistence in newly diagnosed non-valvular atrial fibrillation treated with warfarin or NOAC. A cohort study. Thromb Haemost. (2016) 115:31-9. doi: 10.1160/TH15-04-0350

24. Comarmond C, Jego P, Veyssier-Belot C, Marie I, Mekinian A, ElmalehSachs A, et al. Cessation of oral anticoagulants in antiphospholipid syndrome. Lupus. (2017) 26:1291-6. doi: 10.1177/0961203317699285

25. Yelnik CM, Urbanski G, Drumez E, Caron C, Maillard H, MorellDubois $S$, et al. Anticoagulation withdrawal in antiphospholipid syndrome: a retrospective matched-control study. Lupus. (2018) 27:357-64. doi: 10.1177/0961203317721751

26. Cohen H, Efthymiou M, Isenberg DA. Use of direct oral anticoagulants in antiphospholipid syndrome. J Thromb Haemost. (2018) 16:102839. doi: $10.1111 /$ jth.14017

27. Goldhaber SZ, Eriksson H, Kakkar A, Schellong S, Feuring M, Fraessdorf $M$, et al. Efficacy of dabigatran versus warfarin in patients with acute venous thromboembolism in the presence of thrombophilia: findings from RE-COVER(R), RE-COVER II, and RE-MEDY. Vasc Med. (2016) 21:50614. doi: $10.1177 / 1358863 X 16668588$

28. Cohen H, Hunt BJ, Efthymiou M, Arachchillage DR, Mackie IJ, Clawson $\mathrm{S}$, et al. Rivaroxaban versus warfarin to treat patients with thrombotic antiphospholipid syndrome, with or without systemic lupus erythematosus (RAPS): a randomised, controlled, open-label, phase $2 / 3$, non-inferiority trial. Lancet Haematol. (2016) 3:e426-36. doi: 10.1016/S2352-3026(16)30079-5

29. Pengo V, Denas G, Zoppellaro G, Jose SP, Hoxha A, Ruffatti A, et al. Rivaroxaban vs warfarin in high-risk patients with antiphospholipid syndrome. Blood. (2018) 132:1365-71. doi: 10.1182/blood-2018-04-8 48333

30. Ordi-Ros J, Saez-Comet L, Perez-Conesa M, Vidal X, Riera-Mestre A, CastroSalomo A, et al. Rivaroxaban versus vitamin $\mathrm{K}$ antagonist in antiphospholipid syndrome: a randomized noninferiority trial. Ann Intern Med. (2019) 171:685-94. doi: 10.7326/M19-0291

31. Malec K, Goralczyk T, Undas A. The use of direct oral anticoagulants in 56 patients with antiphospholipid syndrome. Thromb Res. (2017) 152:937. doi: 10.1016/j.thromres.2016.12.009

32. Malec K, Broniatowska E, Undas A. Direct oral anticoagulants in patients with antiphospholipid syndrome: a cohort study. Lupus. (2020) 29:3744. doi: $10.1177 / 0961203319889156$
33. Legault K, Blostein M, Carrier M, Khan S, Schulman S, Shivakumar $\mathrm{S}$, et al. A single-arm feasibility cohort study of rivaroxaban in antiphospholipid syndrome. Pilot Feasibility Stud. (2020) 6:52. doi: 10.1186/s40814-020-00614-0

34. Betancur JF, Bonilla-Abadia F, Hormaza AA, Jaramillo FJ, Canas CA, Tobon GJ. Direct oral anticoagulants in antiphospholipid syndrome: a real life case series. Lupus. (2016) 25:658-62. doi: 10.1177/0961203315 624555

35. Haladyj E, Olesinska M. Rivaroxaban - a safe therapeutic option in patients with antiphospholipid syndrome? Our experience in 23 cases. Reumatologia. (2016) 54:146-9. doi: 10.5114/reum.2016. 61217

36. Son M, Wypasek E, Celinska-Lowenhoff M, Undas A. The use of rivaroxaban in patients with antiphospholipid syndrome: a series of 12 cases. Thromb Res. (2015) 135:1035-6. doi: 10.1016/j.thromres.2015. 01.028

37. Sciascia S, Breen K, Hunt BJ. Rivaroxaban use in patients with antiphospholipid syndrome and previous venous thromboembolism. Blood Coagul Fibrinolysis. (2015) 26:476-7. doi: 10.1097/MBC.0000000000000247

38. Noel N, Dutasta F, Costedoat-Chalumeau N, Bienvenu B, Mariette X, Geffray L, et al. Safety and efficacy of oral direct inhibitors of thrombin and factor Xa in antiphospholipid syndrome. Autoimmun Rev. (2015) 14:6805. doi: 10.1016/j.autrev.2015.03.007

39. Resseguier AS, Pereira B, Rieu V, Le Guenno G, Grobost V, Ruivard M. Direct oral anticoagulants: an alternative treatment for thrombotic antiphospholipid syndrome? Lupus. (2017) 26:1297-303. doi: 10.1177/0961203317701841

40. Sato T, Nakamura H, Fujieda Y, Ohnishi N, Abe N, Kono M, et al. Factor Xa inhibitors for preventing recurrent thrombosis in patients with antiphospholipid syndrome: a longitudinal cohort study. Lupus. (2019) 28:1577-82. doi: 10.1177/0961203319881200

41. Daei M, Khalili H, Heidari Z. Direct oral anticoagulant safety during breastfeeding: a narrative review. Eur J Clin Pharmacol. (2021). doi: 10.1007/s00228-021-03154-5. [Epub ahead of print].

42. Konstantinides SV, Meyer G, Becattini C, Bueno H, Geersing GJ, Harjola VP, et al. 2019 ESC Guidelines for the diagnosis and management of acute pulmonary embolism developed in collaboration with the European Respiratory Society (ERS). Eur Heart J. (2020) 41:543-603. doi: 10.1093/eurheartj/ehz405

43. Ortel TL, Neumann I, Ageno W, Beyth R, Clark NP, Cuker A, et al. American Society of Hematology 2020 guidelines for management of venous thromboembolism: treatment of deep vein thrombosis and pulmonary embolism. Blood Adv. (2020) 4:4693-738. doi: 10.1182/bloodadvances.2020001830

44. McCormack T, Harrisingh MC, Horner D, Bewley S, Guideline C. Venous thromboembolism in adults: summary of updated NICE guidance on diagnosis, management, and thrombophilia testing. BMJ. (2020) 369:m1565. doi: 10.1136/bmj.m1565

45. Arachchillage DRJ, Gomez K, Alikhan R, Anderson JAM, Lester W, Laffan $\mathrm{M}$, et al. Addendum to British Society for Haematology Guidelines on Investigation and Management of Antiphospholipid syndrome, 2012 (Br. J. Haematol. 2012; 157: 47-58): use of direct acting oral anticoagulants. $B r \mathrm{~J}$ Haematol. (2020) 189:212-5. doi: 10.1111/bjh.16308

46. Zuily S, Cohen H, Isenberg D, Woller SC, Crowther M, Dufrost V, et al. Use of direct oral anticoagulants in patients with thrombotic antiphospholipid syndrome: guidance from the scientific and standardization committee of the international society on thrombosis and haemostasis. J Thromb Haemost. (2020) 18:2126-37. doi: 10.1111/jth.14935

47. Tektonidou MG, Andreoli L, Limper M, Amoura Z, Cervera R, CostedoatChalumeau $\mathrm{N}$, et al. EULAR recommendations for the management of antiphospholipid syndrome in adults. Ann Rheum Dis. (2019) 78:1296304. doi: 10.1136/annrheumdis-2019-215213

48. Woller SC, Stevens SM, Kaplan DA, Branch DW, Aston VT, Wilson EL, et al. Apixaban for the secondary prevention of thrombosis among patients with antiphospholipid syndrome: study rationale and design (ASTRO-APS). Clin Appl Thromb Hemost. (2016) 22:239-47. doi: 10.1177/10760296156 15960

49. Testa S, Legnani C, Antonucci E, Paoletti O, Dellanoce C, Cosmi B, et al. Drug levels and bleeding complications in atrial fibrillation patients 
treated with direct oral anticoagulants. J Thromb Haemost. (2019) 17:106472. doi: $10.1111 /$ jth.14457

50. Vrijens B, Heidbuchel H. Non-vitamin K antagonist oral anticoagulants: considerations on once- vs. twice-daily regimens and their potential impact on medication adherence. Europace. (2015) 17:514-23. doi: 10.1093/europace/euu311

51. Testa S, Paoletti O, Legnani C, Dellanoce C, Antonucci E, Cosmi B, et al. Low drug levels and thrombotic complications in high-risk atrial fibrillation patients treated with direct oral anticoagulants. J Thromb Haemost. (2018) 16:842-8. doi: $10.1111 /$ jth. 14001

Conflict of Interest: The authors declare that the research was conducted in the absence of any commercial or financial relationships that could be construed as a potential conflict of interest.
Publisher's Note: All claims expressed in this article are solely those of the authors and do not necessarily represent those of their affiliated organizations, or those of the publisher, the editors and the reviewers. Any product that may be evaluated in this article, or claim that may be made by its manufacturer, is not guaranteed or endorsed by the publisher.

Copyright (C) 2021 Pastori, Menichelli, Cammisotto and Pignatelli. This is an open-access article distributed under the terms of the Creative Commons Attribution License (CC BY). The use, distribution or reproduction in other forums is permitted, provided the original author(s) and the copyright owner(s) are credited and that the original publication in this journal is cited, in accordance with accepted academic practice. No use, distribution or reproduction is permitted which does not comply with these terms. 